\title{
EFICIÊNCIA DE EXTRATORES DE FÓSFORO EM DOIS LATOSSOLOS DO MATO GROSSO DO SUL ${ }^{1}$
}

\author{
WILLIAM MARRA SILVA ${ }^{2}$, AMOACY CARVALHO FABRÍCIO ${ }^{3}$, MARLENE ESTEVÃO MARCHETTI ${ }^{4}$, \\ CARLOS HISSAO KURIHARA ${ }^{5}$, SHIZUO MAEDA ${ }^{5}$ e LUÍS CARLOS HERNANI ${ }^{3}$
}

\begin{abstract}
RESUMO - Com o objetivo de avaliar a eficiência de três extratores de P em dois latossolos (LEa e LRa) do Mato Grosso do Sul, foi conduzido um experimento em casa de vegetação, com três fontes de P (superfosfato triplo, fosfatos naturais de Araxá e de Gafsa), em cinco doses (0, 50, 150, 450 e $600 \mathrm{mg} \mathrm{P} \mathrm{kg}{ }^{-1}$ de solo). Utilizou-se o feijoeiro como planta-teste. Os parâmetros produção de matéria seca, $\mathrm{P}$ acumulado na parte aérea, altura das plantas e número de folhas trifolioladas foram correlacionados com os teores de $\mathrm{P}$ extraídos pelos métodos de Mehlich-1, Mehlich-3 e resina trocadora de íons. Os métodos da resina e Mehlich-3 foram mais sensíveis às variações de solos. Quanto à eficiência, os extratores classificaram-se na seguinte ordem: resina > Mehlich-3 > Mehlich-1. O método da resina, independentemente do tipo de solo e da fonte de $\mathrm{P}$ utilizada, apresentou as melhores correlações com as características das plantas avaliadas, mostrando-se mais adequado em estimar o P disponível. Os teores de P extraídos entre Mehlich-3 e resina são altamente correlacionados entre si.
\end{abstract}

Termos para indexação: solos, fosfatos, métodos de extração, Mehlich-1, Mehlich-3, resina, feijoeiro.

\section{EFFICIENCY OF PHOSPHORUS EXTRACTORS USING TWO OXISOLS FROM MATO GROSSO DO SUL STATE, BRAZIL}

\begin{abstract}
With the objective of evaluating the efficiency of three phosphorus extractors in two Mato Grosso do Sul State oxisols, in Brazil, one greenhouse experiment was carried out with three $P$ sources (triple superphosphate, Araxá rock phosphate and Gafsa rock phosphate), all in five levels ( 0 , $50,150,450$, and $600 \mathrm{mg}$ per $\mathrm{kg}$ of soil). Common bean was used as test plant. In order to evaluate the phosphorus availability in the soils, the dry matter yield, the above ground phosphorus content, the plants height and the number of trifoliate leaves were correlated with the extracted phosphorus by Mehlich-1, Mehlich-3 and ion exchange resin methods. Mehlich-3 and resin were more sensitive to soil variations. According to their efficiencies, the extractors were classified in the following order: resin > Mehlich-3 > Mehlich-1. The resin method showed the best correlations with the plants characteristics, thus showing to be the most suitable in forecasting the available $\mathrm{P}$ in different soils and $\mathrm{P}$ sources. The best correlations were yielded by the resin and Mehlich-3 methods.
\end{abstract}

Index terms: soils, phosphates, extraction methods, Mehlich-1, Mehlich-3, resin, edible beans.

\footnotetext{
${ }^{1}$ Aceito para publicação em 26 de fevereiro de 1999.

Extraído da Dissertação de Mestrado do primeiro autor, apresentada à Universidade Federal de Mato Grosso do Sul (UFMS), Dourados, MS.

${ }^{2}$ Eng. Químico, M.Sc., Embrapa-Centro de Pesquisa Agropecuária do Oeste (CPAO), Caixa Postal 661, CEP 79804-970 Dourados, MS. E-mail: william@cpao.embrapa.br

${ }^{3}$ Eng. Agr., Dr., Embrapa-CPAO.

${ }^{4}$ Eng $\underline{a}$ Agr $\underline{a}$, Drạa, DCA/CEUD-UFMS, Caixa Postal 533, CEP 79804-970 Dourados, MS.

${ }^{5}$ Eng. Agr., M.Sc., Embrapa-CPAO.
}

\section{INTRODUÇÃO}

Os diferentes métodos para extração de P não apresentam resultados idênticos, e nem sempre se correlacionam significativamente entre si, dificultando comparações. Há, portanto, necessidade de padronizá-los, e calibrá-los regionalmente. Quando isto é feito, pode-se chegar a soluções razoáveis do ponto de vista prático (Raij, 1991). No Brasil, o método de extração mais utilizado é o Mehlich-1, mas, em alguns Estados, empregam-se também as resinas de troca iônica. 
Em solos corrigidos com fosfatos de baixa solubilidade, como os fosfatos naturais brasileiros, a utilização de extratores ácidos, como o Mehlich-1, proporciona valores superestimados do $\mathrm{P}$ disponível, e não apresentam boas correlações com os rendimentos das culturas ou com as quantidades absorvidas do elemento (Doll et al., 1960; Barnes \& Kamprath, 1975; Sfredo et al., 1979). Em solos argilosos, como os Latossolos Roxos, os extratores ácidos subestimam o teor do $\mathrm{P}$ disponível, mesmo quando o histórico da área indica ausência de respostas de plantas à adubação fosfatada (Raij, 1991). Apesar disso, os extratores ácidos apresentam, como grande vantagem para uso rotineiro em laboratório, o fato de possibilitarem extratos límpidos (Raij et al., 1984) e facilidade de execução de análise, devido à maior velocidade de decantação das suspensões, o que dispensa o processo de filtração.

Teoricamente, a utilização de resinas de troca iônica corrige ou minimiza os problemas apresentados pelos extratores ácidos (Raij et al., 1986), como os mencionados anteriormente. A resina não tem seu poder de exaustão alterado em presença de material de solos com maior fator capacidade, e não subestimam, assim, o P lábil, e não é sensível às formas nãolábeis, como as de $\mathrm{P}-\mathrm{Ca}$. Este método, porém, é mais complexo que os demais, e necessita de longo período de extração (16 horas), separação da resina e extração do P da resina (Raij, 1992). Por outro lado, apresenta melhor correlação com respostas à adubação fosfatada, analogia com extração da planta muito superior aos dos outros métodos, além de não incluir nenhum agente químico de ação específica sobre os fosfatos do solo (Raij et al., 1982, 1984).

Na década de 80, novos extratores desenvolvidos demonstraram superioridade sobre os em uso atualmente. Um exemplo é o Mehlich-3 (Mehlich, 1984), que é um método de extração ácida, constituído por uma série de compostos químicos com atuação específica sobre determinadas formas de $\mathrm{P}$ do solo. Em solos da região dos cerrados cultivados com soja, em casa de vegetação, o Mehlich-3 foi superior ao Bray-1 e à resina (Lins \& Cox, 1989). Brasil \& Muraoka (1997), trabalhando com solos da Amazônia Oriental, submetidos a diferentes fontes e doses de $\mathrm{P}$, em casa de vegetação, verificaram, de maneira geral, que o extrator Mehlich-3 destacou-se dos demais, mostrando-se mais adequado em prever a disponibilidade de $\mathrm{P}$ para as plantas.

O objetivo deste trabalho foi o de comparar, em casa de vegetação, a eficiência dos extratores Mehlich-1, Mehlich-3 e resina de troca iônica na avaliação de $\mathrm{P}$ disponível para o feijoeiro em dois solos: Latossolo Roxo álico e Latossolo VermelhoEscuro álico, submetidos a diferentes fontes e doses de fosfato.

\section{MATERIAL E MÉTODOS}

Para este estudo, utilizaram-se amostras de dois solos representativos do Mato Grosso do Sul, um Latossolo Vermelho-Escuro álico (LEa), textura franco-argilo-arenoso e um Latossolo Roxo álico (LRa), textura argila pesada. Coletaram-se amostras da camada 0-20 cm, após remoção dos resíduos e vegetação. Após a secagem ao ar, parte do material foi submetido à tamisagem em peneiras de $4 \mathrm{e}$ $2 \mathrm{~mm}$ de abertura. A terra que passou pela peneira de $4 \mathrm{~mm}$ foi utilizada no experimento e a tamisada a $2 \mathrm{~mm}$ foi submetida às análises físicas e químicas. Os resultados dessas determinações estão na Tabela 1 .

$\mathrm{O}$ experimento foi conduzido em casa de vegetação, no Núcleo Experimental de Ciências Agrárias (NCA), da Universidade Federal de Mato Grosso do Sul (UFMS), no período de abril a agosto de 1996. Empregaram-se três fontes de $\mathrm{P}$ (superfosfato triplo, fosfatos naturais de Araxá e de Gafsa), em cinco doses (0, 50, 150, 450 e $600 \mathrm{mg} \mathrm{P} \mathrm{kg}^{-1}$ de solo). Ensaio preliminar de incubação foi desenvolvido, objetivando definir as doses de corretivo (mistura de $\mathrm{CaCO}_{3}$ e $\mathrm{MgCO}_{3}$ p.a., na relação molar de 4:1), necessárias à elevação do $\mathrm{pH}$ em $\mathrm{H}_{2} \mathrm{O}$ das amostras próximo ao valor 6,0 , para os dois solos. Utilizaram-se amostras de $4 \mathrm{~kg}$ de terra, acondicionadas em vasos de plástico com capacidade de cinco litros. Os tratamentos foram arranjados no esquema fatorial $5 \times 3 \times 2$, no delineamento experimental inteiramente casualizado, com quatro repetições.

O fosfato de Araxá foi aplicado nos solos 30 dias antes da calagem, enquanto o superfostato triplo e o fosfato de Gafsa foram aplicados 30 dias após a calagem (na semeadura). A quantidade de fertilizante aplicada em cada dose de $\mathrm{P}$ foi calculada com base no teor total de $\mathrm{P}_{2} \mathrm{O}_{5}$ de cada fonte, correspondente a 42, 28 e $24 \%$ para o superfosfato triplo, fosfato de Gafsa e Araxá, respectivamente.

Como planta-teste, utilizou-se o feijoeiro (Phaseolus vulgaris L.), cultivar FT 10 do grupo Carioca. Semearamse dez sementes por vaso, previamente tratadas com 
TABELA 1. Atributos químicos e físicos das amostras dos solos utilizados no experimento.

\begin{tabular}{llcc}
\hline Atributos & Determinação & \multicolumn{2}{c}{ Solos } \\
\cline { 3 - 4 } & & 4,8 & LEa \\
\hline $\mathrm{pH}(1: 2,5) \mathrm{em} \mathrm{H}_{2} 0$ & Potenciometria & 4,1 & 4,7 \\
$\mathrm{pH}(1: 2,5) \mathrm{em} \mathrm{CaCl}_{2} 0,01 \mathrm{~mol} \mathrm{~L}^{-1}$ & Potenciometria & 29 & 4,0 \\
$\mathrm{M} . \mathrm{O} .\left(\mathrm{g} \mathrm{kg}^{-1}\right)$ & Walkley-Black & 4,0 & 22 \\
$\mathrm{P}\left(\mathrm{mg} \mathrm{dm}^{-3}\right)$ & Mehlich-1 & 3,2 & 3,0 \\
$\mathrm{P}\left(\mathrm{mg} \mathrm{dm}^{-3}\right)$ & Mehlich-3 & 10,8 & 4,8 \\
$\mathrm{P}\left(\mathrm{mg} \mathrm{dm}^{-3}\right)$ & Resina & 0,13 & 9,2 \\
$\mathrm{~K}\left(\mathrm{cmol}_{\mathrm{c}} \mathrm{dm}^{-3}\right)$ & Mehlich-1 & 1,1 & 0,12 \\
$\mathrm{Ca}^{2+}\left(\mathrm{cmol}_{\mathrm{c} \mathrm{dm}} \mathrm{dm}^{-3}\right)$ & KCl 1N & 0,4 & 0,2 \\
$\mathrm{Mg}^{2+}\left(\mathrm{cmol}_{\mathrm{c}} \mathrm{dm}^{-3}\right)$ & KCl 1N & 2,1 & 0,1 \\
$\mathrm{Al}^{3+}\left(\mathrm{cmol}_{\mathrm{c}} \mathrm{dm}^{-3}\right)$ & KCl 1N & 9,3 & 1,9 \\
$\mathrm{H}^{+}+\mathrm{Al}^{3+}\left(\mathrm{cmol}_{\mathrm{c}} \mathrm{dm}^{-3}\right)$ & Acetato de cálcio & 56 & 8,6 \\
$\mathrm{Saturação} \mathrm{de} \mathrm{Al}(\%)_{\mathrm{CTC} \mathrm{efetiva}\left(\mathrm{cmol}_{\mathrm{c}} \mathrm{dm}^{-3}\right)}$ & Calculado & 3,73 & 82 \\
$\mathrm{CTC}_{\left(\mathrm{cmol}_{\mathrm{c}} \mathrm{dm}^{-3}\right)}$ & Calculado & 10,9 & 2,32 \\
Saturação em bases $(\%)$ & Calculado & 15 & 9,0 \\
Areia $\left(\mathrm{g} \mathrm{kg}^{-1}\right)$ & Calculado & 230 & 5 \\
Silte $\left(\mathrm{g} \mathrm{kg}^{-1}\right)$ & Bouyoucos & 150 & 620 \\
Argila $\left(\mathrm{g} \mathrm{kg}^{-1}\right)$ & Bouyoucos & 620 & 80 \\
Densidade do solo $\left(\mathrm{g} \mathrm{cm}^{-3}\right)$ & Bouyoucos & 1,19 & 300 \\
\hline
\end{tabular}

fungicida (Benlate, na dosagem de $100 \mathrm{~g} / 100 \mathrm{~kg}$ de sementes). Após a emergência, fez-se o desbaste, deixando-se três plantas por vaso. Fez-se uma adubação básica de $\mathrm{N}, \mathrm{K}$ e $\mathrm{S}$ constituída, respectivamente, de 300, 150 e $50 \mathrm{mg} \mathrm{kg}^{-1}$; e de micronutrientes $\mathrm{B}, \mathrm{Cu}, \mathrm{Fe}, \mathrm{Mn}, \mathrm{Zn}, \mathrm{Mo}$, utilizando-se, respectivamente, as seguintes dosagens: $0,5,1,5,5,0,3,0,5,0$ e $0,1 \mathrm{mg} \mathrm{kg}^{-1}$ (Malavolta, 1980), aplicados via solução.

Durante o desenvolvimento das plantas, diariamente adicionou-se água destilada nos vasos, visando manter o solo com 70\% da capacidade de campo. Aos 56 dias após a semeadura, no estádio de floração plena, avaliaram-se a altura das plantas, a contagem do número de folhas trifolioladas, e o corte da parte aérea das plantas rente ao solo.

A parte aérea foi lavada com água corrente, e, posteriormente, água destilada, submetida a uma pré-secagem, e acondicionada em saco de papel perfurado, para completar a secagem em estufa com ar forçado, a $70^{\circ} \mathrm{C}$, até peso constante. A seguir, a matéria seca foi pesada e moída em moinho tipo Willey, provido de peneira de aço inoxidável com 20 malhas por polegada $(0,42 \mathrm{~mm})$. Determinou-se a matéria seca total e o teor de $\mathrm{P}$ no tecido vegetal. O P foi determinado por via úmida, segundo Malavolta et al. (1989), a qual consistiu na digestão nítrico-perclórica, e determinação do elemento, pelo método colorimétrico do metavanadato.
Após a colheita das plantas, procedeu-se à coleta de amostras de terra de cada vaso. As amostras foram homogeneizadas, secadas ao ar, moídas, e passadas em peneira com malha de $2 \mathrm{~mm}$ de abertura, para a obtenção de terra fina, secada ao ar (TFSA). Determinou-se o teor de P disponível extraído por Mehlich-1, segundo Embrapa (1979); Mehlich-3, de acordo com Mehlich (1984); e pelo método da resina trocadora de íons, conforme Raij et al. (1986).

A eficiência dos extratores foi avaliada empregando-se como parâmetro de disponibilidade de $\mathrm{P}$ a correlação entre teores de $\mathrm{P}$ no solo, extraídos pelos diferentes métodos, e a produção de matéria seca, $\mathrm{P}$ acumulado na parte aérea, número de folhas trifolioladas, e altura das plantas. Também foram realizadas correlações entre os teores de $\mathrm{P}$ extraído dos solos pelos diferentes extratores.

\section{RESULTADOS E DISCUSSÃO}

Correlação entre as quantidades de P extraído e as características de crescimento do feijoeiro, considerando as fontes de $P$ utilizadas

As fontes de $\mathrm{P}$ influenciaram significativamente as correlações entre o $\mathrm{P}$ extraído por diferentes métodos e as características do feijoeiro (Tabela 2). 
TABELA 2. Correlação linear entre os teores de $\mathbf{P}$ no solo, extraídos pelos métodos Mehlich-1, Mehlich-3 e resina trocadora de íons, e a altura de plantas (ALP), o número de folhas trifolioladas (NFT), a matéria seca da parte aérea (MSPA) e o acúmulo de $P$ na parte aérea (ACPA) do feijoeiro, em relação à cada fonte de $P$.

\begin{tabular}{|c|c|c|c|c|}
\hline Método & ALP & NFT & MSPA & ACPA \\
\hline & \multicolumn{4}{|c|}{ Fosfato de Araxá } \\
\hline Mehlich-1 & $0,644^{*}$ & $0,710^{*}$ & $0,782 * *$ & $0,758 * *$ \\
\hline Mehlich-3 & $0,281^{\mathrm{ns}}$ & $0,353^{\text {ns }}$ & $0,465^{\mathrm{ns}}$ & $0,421^{\mathrm{ns}}$ \\
\hline \multirow[t]{2}{*}{ Resina } & $0,908 * *$ & $0,944 * *$ & $0,957 * *$ & $0,953^{* *}$ \\
\hline & \multicolumn{4}{|c|}{ Fosfato de Gafsa } \\
\hline Mehlich-1 & $0,839 * *$ & $0,888 * *$ & $0,885^{* *}$ & $0,867 * *$ \\
\hline Mehlich-3 & $0,698^{*}$ & $0,761^{* *}$ & $0,743^{*}$ & $0,714 *$ \\
\hline \multirow[t]{2}{*}{ Resina } & $0,955^{* *}$ & $0,965^{* *}$ & $0,976^{* *}$ & $0,984^{*}$ \\
\hline & \multicolumn{4}{|c|}{ Superfosfato triplo } \\
\hline Mehlich-1 & $0,680^{*}$ & $0,798^{* *}$ & $0,778^{* *}$ & $0,885^{* *}$ \\
\hline Mehlich-3 & $0,605^{\text {ns }}$ & $0,714^{*}$ & $0,706^{*}$ & $0,812 * *$ \\
\hline Resina & $0,741 *$ & $0,887^{* *}$ & $0,858^{* *}$ & $0,964 * *$ \\
\hline
\end{tabular}

n.s. $*$ e ** Não-significativo e significativo a $5 \%$ e $1 \%$ de probabilidade, respectivamente.

Verificaram-se elevados coeficientes de correlação obtidos entre o P extraído pelo Mehlich-1 e o P acumulado na parte aérea, nos solos tratados com fosfato solúvel $\left(\mathrm{r}=0,885^{* *}\right)$ e fosfato de rocha sedimentar $\left(\mathrm{r}=0,867^{* *}\right)$. Com o uso de uma fonte de rocha ígnea, a correlação foi menos acentuada $\left(\mathrm{r}=0,758^{* *}\right)$, o que pode estar relacionado ao fato de o extrator Mehlich-1 dissolver resíduos não disponíveis às plantas, quando se usa adubo de baixa solubilidade (Doll et al., 1960; Barnes \& Kamprath, 1975). Segundo Raij (1991), o pH dos extratores ácidos é inadequado para a solubilização de fosfatos de ferro e alumínio, sendo, porém, extremamente favorável para a extração de fosfatos de cálcio, mesmo em formas não-lábeis.

Com o método da resina, as correlações entre as características de crescimento da planta avaliadas foram superiores aos demais métodos, o que demonstra a eficiência desse extrator, tanto para os fosfatos de rocha de origem ígnea e sedimentar, como para a fonte mais solúvel. Esses resultados são semelhantes aos verificados por Raij \& Diest (1980), Cabala \&
Wild (1982), Braga et al. (1991) e Holanda et al. (1994), que o consideram como um dos mais adequados para estimativa do P disponível em solos que receberam diferentes fontes de fosfato.

Os resultados obtidos pelo extrator Mehlich-3 mostraram correlações não-significativas entre o $\mathrm{P}$ extraído e as respostas da planta, nos solos tratados com fosfato de Araxá, sendo que para as demais fontes de $\mathrm{P}$ obtiveram-se as mais baixas correlações, em relação aos outros métodos de extração (Tabela 2). Esses resultados discordam de Brasil \& Muraoka (1997), que obtiveram coeficiente de correlação superior para o extrator de Mehlich-3, o qual distinguiu, com certa versatilidade, solos tratados com fosfato natural, em relação aos que receberam aplicação de fosfatos solúveis. Esses resultados podem ser comparados aos obtidos por Smith et al. (1957), que verificaram que o extrator Bray 1, cuja ação sobre as frações de $\mathrm{P}$ no solo é semelhante à do Mehlich-3, demonstrou diferenciação de extração de solos tratados com fontes solúveis daqueles adubados com fosfato natural. Estes autores citam, ainda, que as porções do fosfato natural não solubilizadas nos solos não foram atingidas pelo extrator. Portanto, é provável que as baixas correlações obtidas com esse extrator de Mehlich-3 sejam devidas ao fato de as plantas removerem $\mathrm{P}$ solubilizado dos fosfatos naturais, antes que estes passem para a forma lábil, ao passo que o extrator parece extrair outras formas.

Nos tratamentos que receberam aplicação de superfosfato triplo, observaram-se elevados coeficientes de correlação em todos os extratores. Esses resultados demostraram que as reações do solo com os fertilizantes são quase totalmente completadas, quando são utilizados fertilizantes mais solúveis. Assim, tanto a resina como os extratores ácidos podem ser utilizados satisfatoriamente; o que está de acordo com os resultados obtidos por outros pesquisadores (Sfredo et al., 1979; Corrêa \& Haag, 1993; Holanda et al., 1994). A mais baixa correlação obtida com o Mehlich-3, apesar de o superfosfato triplo não ser constituído de fosfato insolúvel (Barbosa Filho et al., 1987), talvez possa ser explicada pela presença de Ca proveniente da calagem e da fonte solúvel. Isso pode ter afetado a sua sensibilidade de extração do $\mathrm{P}$ aplicado, resultando em menor extração de $\mathrm{P}$ nas doses mais elevadas. 
Correlação entre as quantidades de $P$ extraído e as características de crescimento do feijoeiro, considerando os tipos de solos

Para avaliar a sensibilidade dos métodos de extração de P nos solos utilizados, os dados foram agrupados por solo, efetuando-se correlações entre os teores de $\mathrm{P}$ extraído e as características de crescimento das plantas de feijão (Tabela 3).

$\mathrm{O}$ extrator de Mehlich-1 apresentou as mais baixas correlações com as características das plantas de feijão, sendo que no LEa os coeficientes de correlação foram significativos quanto às características altura das plantas e número de folhas trifolioladas, e no LRa não houve significância quanto a qualquer das correlações efetuadas. Esses valores devem estar relacionados à elevada capacidade de extração de $\mathrm{P}$, em virtude de dissolução de formas de $\mathrm{P}$ não disponíveis às plantas, mesmo em situações em que as plantas possuem dificuldades em absorver o elemento. Sua ação consiste na solubilização de fosfatos de cálcio, de alumínio e de ferro, pelos íons hidrogênio presentes. A baixa correlação no LRa, observada, com a fonte solúvel, parece estar relacionada ao

TABELA 3. Correlação linear entre os teores de $\mathbf{P}$ no solo, extraídos pelos métodos de Mehlich-1, Mehlich-3 e resina trocadora de íons, e a altura das plantas (ALP), o número de folhas trifolioladas (NFT), a matéria seca da parte aérea (MSPA) e o acúmulo de $P$ na parte aérea (ACPA) do feijoeiro, em cada solo utilizado.

\begin{tabular}{lllll}
\hline Método & ALP & NFT & MSPA & ACPA \\
\hline \multirow{5}{*}{ Lehlich-1 } & $0,513^{*}$ & $0,521^{*}$ & $0,428^{\mathrm{ns}}$ & $0,362^{\mathrm{ns}}$ \\
Mehlich-3 & $0,860^{* *}$ & $0,910^{*}$ & $0,912^{* *}$ & $0,936^{* *}$ \\
Resina & $0,934^{* *}$ & $0,964^{* *}$ & $0,956^{* *}$ & $0,954^{* *}$ \\
& & & \\
& & Latossolo Roxo álico & \\
Mehlich-1 & $0,402^{\mathrm{ns}}$ & $0,400^{\mathrm{ns}}$ & $0,293^{\mathrm{ns}}$ & $0,251^{\mathrm{ns}}$ \\
Mehlich-3 & $0,691^{* *}$ & $0,845^{* *}$ & $0,794^{* *}$ & $0,887^{* *}$ \\
Resina & $0,786^{* *}$ & $0,894^{* *}$ & $0,834^{* *}$ & $0,879^{* *}$ \\
\hline
\end{tabular}

n.s. * e ** Não-significativo e significativo a $5 \%$ e $1 \%$ de probabilidade respectivamente. fato de que, em solos com altos teores de óxido de ferro e de argila, os teores obtidos normalmente são baixos, pela exaustão do extrator (Thomas \& Peaslee, 1973; Kamprath \& Watson, 1980).

Os maiores valores observados no LEa (Tabela 3), assim como as maiores correlações obtidas, são condizentes com os dados de Kamprath \& Watson (1980), os quais afirmaram que a maior concentração de P em solução, em solos arenosos, está normalmente associada a baixos valores de capacidade tampão. Para a mesma quantidade de P absorvida pelo vegetal haveria, proporcionalmente, maior redução da concentração de $\mathrm{P}$ em solução no solo arenoso do que no argiloso. Cajuste \& Kussow (1974) demonstraram, em solos do Rio Grande do Sul, que a eficiência do extrator é influenciada pelo tipo e teor de argila.

Os coeficientes de correlação obtidos entre o P extraído e a produção de matéria seca ou $\mathrm{P}$ acumulado na parte aérea, assim como as demais características de crescimento avaliadas, demonstraram claramente a sensibilidade dos métodos da resina e Mehlich-3 às variações dos solos (Tabela 3). Esses resultados concordam com os de Ibrikci et al. (1992) e Muniz et al. (1996), que classificaram os extratores quanto à sensibilidade para detectar variações na disponibilidade de $\mathrm{P}$, na seguinte ordem: resina > Mehlich-3 > Olsen > Bray-1 > Mehlich-1. Entretanto, Piha (1993), comparando a resina e o extrator de Mehlich-3, em solos do Zimbabwe, observou que as correlações de extração, nos dois métodos, com o crescimento da planta, variou com a textura do solo. $\mathrm{O}$ autor mostrou que o extrator de Mehlich-3, por ser menos influenciado pela textura do solo, é, portanto, o mais indicado para predizer o estado do P sobre uma larga variação de solos. Por outro lado, Brasil \& Muraoka (1997) demonstraram que os extratores de Mehlich-3 e Bray 1 foram mais sensíveis às variações de solo do que a resina trocadora de íons. Lins \& Cox (1989), trabalhando com sete solos de cerrado do Brasil, em casa de vegetação, com o teor de argila variando de 120 a $680 \mathrm{~g} \mathrm{~kg}^{-1}$, verificaram que o extrator de Mehlich-3 foi superior ao Bray-1 e à resina, na predição das necessidades de $\mathrm{P}$ para a soja, quando se considerava o teor de argila. Por outro lado, quando se considerava apenas o P extraível, a resina foi melhor. 
Correlação entre as quantidades de $P$ extraído e as características de crescimento do feijoeiro, considerando o experimento no geral

Quando a análise é feita independentemente da fonte de $\mathrm{P}$ e do solo utilizado, observa-se que os teores de $\mathrm{P}$ extraídos foram melhor correlacionados com as características avaliadas, quando se usou a resina (Tabela 4). Estes resultados demonstraram a superioridade do método da resina sobre os demais, o que confirma as conclusões de Raij (1978), Fixen \& Grove (1990) e Silva (1991). Os coeficientes de correlação encontrados neste experimento no que tange aos extratores de Mehlich-1 e resina estão dentro do intervalo encontrado por Fixen \& Grove (1990), cuja amplitude de variação foi de 0,25 a 0,91 e de 0,69 a 0,98 , respectivamente.

No Estado de São Paulo, a resina de troca iônica é usada para análise de solo, não somente no tocante ao $\mathrm{P}$, mas também no que tange ao $\mathrm{Ca}$, ao $\mathrm{Mg}$ e ao $\mathrm{K}$, com a utilização simultânea de resinas aniônicas e catiônicas na mesma extração (Raij et al., 1986). Raij (1994) cita que a extração com a resina de troca iônica provavelmente é o melhor método para avaliação, e só não é usado rotineiramente devido à preferência por métodos mais simples. $\mathrm{O}$ autor salienta que o método da resina de troca iônica é uma das alternativas mais promissoras como extrator universal, se problemas de procedimento analítico forem resolvidos.

Por outro lado, o método de extração de Mehlich-3, apesar de ter sido introduzido recentemente, tem chamado a atenção de muitos pesquisadores, visan-

TABELA 4. Correlação linear geral entre os teores de $P$ no solo, extraídos pelos métodos de Mehlich-1, Mehlich-3 e resina trocadora de íons, e a altura de plantas (ALP), 0 número de folhas trifolioladas (NFT), a matéria seca da parte aérea (MSPA) e o acúmulo de $P$ na parte aérea (ACPA) do feijoeiro.

\begin{tabular}{lllll}
\hline Método & ALP & NFT & MSPA & ACPA \\
\hline Mehlich-1 & $0,420^{*}$ & $0,428^{*}$ & $0,340^{\text {ns }}$ & $0,294^{\text {ns }}$ \\
Mehlich-3 & $0,656^{* *}$ & $0,743^{* *}$ & $0,742^{* *}$ & $0,802^{* *}$ \\
Resina & $0,851^{* *}$ & $0,925^{* *}$ & $0,891 * *$ & $0,915 * *$ \\
\hline $\begin{array}{l}\text { n.s. } \\
\text { respect e ** Não-significativo e significativo a } 5 \% \text { e } 1 \% \text { de probabilidade, }\end{array}$
\end{tabular}

Pesq. agropec. bras., Brasília, v.34, n.12, p.2277-2285, dez. 1999 do à determinação dos teores de $\mathrm{P}$ que se encontram à disposição das plantas, assim como outros nutrientes. Evans \& Mcguire (1990) demonstraram que o extrator Mehlich-3, juntamente com o Mehlich-1, apresentou melhor correlação, não somente com $\mathrm{P}$ mas também com o $\mathrm{Ca}, \mathrm{Mg}$ e $\mathrm{K}$. Resultados relativos à utilização do Mehlich-3 como extrator universal no Brasil foram obtidos por Vasconcellos et al. (1996) em solos de Minas Gerais, onde os extratores de Mehlich-1 e Mehlich-3 atuaram de modo semelhante tanto no tocante ao $\mathrm{P}$ como ao $\mathrm{K}$, principalmente em condições de baixos teores de óxido de ferro. Quanto aos micronutrientes ( $\mathrm{Zn}, \mathrm{Cu}, \mathrm{Fe}$ e $\mathrm{Mn}$ ), os extratores atuaram de forma diferente dos elementos, o que sugere a melhor possibilidade de o Mehlich-3 adequar-se às estimativas da suficiência nutricional.

Correlação entre os teores de $\mathbf{P}$ extraído pelos métodos Mehlich-1, Mehlich-3 e resina trocadora de íons

Os coeficientes de correlação verificados entre o Mehlich-3 e a resina foram altos e significativos a $1 \%$ de probabilidade no geral e no LEa, e a $5 \%$ no LRa (Tabela 5). Esses resultados permitem supor que estes métodos extraíam formas semelhantes e em quantidades proporcionais, de P solúvel, dos solos utilizados, nas condições deste trabalho. Segundo Bahia Filho et al. (1983), as correlações entre os teores de $\mathrm{P}$ disponível obtidas por diferentes extratores têm sido atribuídas à extração preferencial de deter-

TABELA 5. Correlação linear entre os teores de $P$ extraído pelos diferentes métodos nos dois solos.

\begin{tabular}{ccc} 
Mehlich-1 x Mehlich-3 & Mehlich-1 x Resina & Mehlich-3 x Resina \\
\hline $0,619^{*}$ & Latossolo Vermelho-Escuro álico \\
& $0,555^{*}$ & $0,967^{* *}$ \\
$0,568^{*}$ & Latossolo Roxo álico \\
& $0,569^{*}$ \\
& \\
& Geral & $0,965^{*}$ \\
$0,606^{*}$ & $0,537^{* *}$ & $0,845^{* *}$ \\
\hline
\end{tabular}

* e ** Significativo a 5\% e $1 \%$ de probabilidade, respectivamente. 
minada forma de $\mathrm{P}$, associada à maior atividade da forma preferencialmente extraída. Essa explicação parece justificar, em parte, as diferenças entre os extratores, e está de acordo com Piha (1993), que demonstrou que o extrator de Mehlich-3 foi altamente correlacionado em solos com $\mathrm{P}$ ligado ao Al, mesmo em solos derivados de material rico em Fe. Barbosa Filho et al. (1987) verificaram que em solos sob cerrado (LVd e LEd) a forma preferencialmente extraída pela resina foi o P-Al. Segundo Holford (1980), quanto mais similares forem dois extratores na sua sensibilidade ao tamponamento, maior será a correlação entre ambos.

Correlações significativas foram também obtidas entre os métodos de Mehlich-1 e resina trocadora de íons, embora com valores menores que os obtidos na correlação entre este último e o Mehlich-3 (Tabela 5). A explicação seria dada pelas formas predominantes extraídas pelo extrator de Mehlich-1, quando se consideram os fosfatos naturais, em face da sua elevada capacidade de dissolução de apatitas que não reagiram com o solo. De acordo com Hislop \& Cooke (1966), citados por Barbosa Filho et al. (1987), o método da resina reflete melhor os fatores capacidade e intensidade de $\mathrm{P}$ no solo, enquanto o Mehlich-1 representa melhor o fator quantidade (Bahia Filho \& Braga, 1975).

Os valores dos coeficientes de correlação verificados entre os extratores de Mehlich-1 x Mehlich-3 foram semelhantes aos obtidos pelo Mehlich-1 x resina, apesar de os extratores de Mehlich apresentarem comportamentos diferentes nas formas predominantemente extraídas.

\section{CONCLUSÕES}

1. Os métodos da resina e Mehlich-3 são mais sensíveis às variações de solos.

2. Quanto à eficiência, os extratores classificamse na seguinte ordem: resina > Mehlich-3 > Mehlich-1.

3. O método da resina, independentemente do tipo de solo e da fonte de P utilizada, apresenta as melhores correlações com as características das plantas avaliadas, mostrando-se mais adequado em estimar o P disponível.
4. Os teores de P extraídos entre Mehlich-3 e resina são altamente correlacionados entre si.

\section{REFERÊNCIAS}

BAHIA FILHO, A.F.C.; BRAGA, J.M. Fósforo em latossolos do Estado de Minas Gerais. II. Quantidade de fósforo "disponível". Revista Ceres, Viçosa, v.22, p.50-61, 1975.

BAHIA FILHO, A.F.C.; BRAGA, J.M.; RIBEIRO, A.C.; NOVAIS, R.F. Sensibilidade de extratores químicos à capacidade-tampão de fósforo. Revista Brasileira de Ciência do Solo, Campinas, v.7, p.243-249, 1983.

BARBOSA FILHO, M.P.; KINJO, T.; MURAOKA, T. Relações entre fósforo "extraível”, frações inorgânicas de fósforo e crescimento do arroz em função de fontes de fósforo, calagem e tempo de incubação. Revista Brasileira de Ciência do Solo, Campinas, v.11, p.147-155, 1987.

BARNES, J.S.; KAMPRATH, E.J. Availability of North Caroline rock phosphate applied to soils. Raleigh: North Carolina State University, 1975. 23p. (Agricultural Experiment Station. Technical Bulletin, 229).

BRAGA, N.R.; MASCARENHAS, H.A.A.; BULISANI, E.A.; RAIJ, B. van; FEITOSA, C.T.; HIROCE, R. Eficiência agronômica de nove fosfatos em quatro cultivos consecutivos de soja. Revista Brasileira de Ciência do Solo, Campinas, v.15, p.315-319, 1991.

BRASIL, E.D.; MURAOKA, T. Extratores de fósforo em solos da Amazônia tratados com fertilizantes fosfatados. Revista Brasileira de Ciência do Solo, Viçosa, v.21, p.599-606, 1997.

CABALA, R.P.; WILD, A. Direct use of low grade phosphate rock Brasil as fertilizer. Effect of reaction time in soil. Plant and Soil, Hague, v.65, p.351$362,1982$.

CAJUSTE, L.J.; KUSSOW, W.R. Use and limitations on the North Caroline Method to predict available phosphorus in some oxisols. Tropical Agriculture, Trinidad, v.51, p.246-252, 1974.

CORRÊA, L. de A.; HAAG, H.P. Disponibilidade de fósforo pelos extratores de Mehlich-1 e resina em Latossolo Vermelho-Amarelo álico, cultivado com três gramíneas forrageiras. Scientia Agrícola, Piracicaba, v.50, p.287-294, 1993.

Pesq. agropec. bras., Brasília, v.34, n.12, p.2277-2285, dez. 1999 
DOLL, E.C.; MILLER, H.F.; FREEMAN, J.F. Initial and residual effects of rock phosphate and superphosphate. Agronomy Journal, Madison, v.52, p.246-250, 1960.

EMBRAPA. Serviço Nacional de Levantamento e Conservação de Solos (Rio de Janeiro, RJ). Manual de métodos de análise de solo. Rio de Janeiro, 1979. Não paginado.

EVANS, C.E.; MCGUIRE, J.A. Comparison of soil test extractants on Alabama soils. Communications in Soil Science and Plant Analysis, New York, v.21, p.1037-1050, 1990.

FIXEN, P.E.; GROVE, J.H. Testing soils for phosphorus In: WESTERMAN, R.L. (Ed.). Soil testing and plant analysis. 3.ed. Madison: SSSA, 1990. ch.7, p.141-180. (SSSA. Book Series, 3).

HOLANDA, J.S.; BRASIL, E.C.; SALVIANO, A.A.C.; CARVALHO, M.C.S.; RODRIGUES, M.R.L.; MALAVOLTA, E. Eficiência de extratores de fósforo num solo adubado com fosfatos e cultivado com arroz. In: REUNIÃO BRASILEIRA DE FERTILIDADE DO SOLO, 21., 1994, Petrolina. Anais. Petrolina: SBCS/Embrapa-CPATSA, 1994. p.46-48.

HOLFORD, I.C.R. Effects of phosphate buffer capacity on critical levels and relationships between soil tests and labile phosphate in wheat-growing soils. Australian Journal of Soil Research, East Melbourne, v.18, p.405-414, 1980.

IBRIKCI, H.; HANLON, E.A.; RECHCIGL, J.E. Initial calibration and correlation of inorganic phosphorus soil test methods with bahiagrass field trial. Communications in Soil Science and Plant Analysis, New York, v.23, p.2569-2579, 1992.

KAMPRATH, E.J.;WATSON, M.E. Conventional soil and tissue tests for assessing the phosphorus status of soils. In: KHASAWNEH, F.E.; SAMPLE, E.C.; KAMPRATH, E.J. (Eds.). The role of phosphorus in agriculture. Madison: ASA/CSSA/SSSA, 1980. p.433-469.

LINS, I.D.G.; COX, F.R. Effect of extractant and selected soil properties on predicting the correct phosphorus fertilization of soybean. Soil Science Society of America. Journal, Madison, v.53, p.813-816, 1989.

MALAVOLTA, E. Elementos de nutrição mineral de plantas. São Paulo: Agronômica Ceres, 1980. 251p.
MALAVOLTA, E.; VITTI, C.G.; OLIVEIRA, S.A. Avaliação do estado nutricional das plantas: princípios e aplicações. Piracicaba: POTAFOS, 1989. 201p.

MEHLICH, A. Mehlich-3 soil test extractant: a modification of Mehlich-2 extractant. Communications in Soil Science and Plant Analysis, New York, v.15, p.1409-1416, 1984.

MUNIZ, A.S.; RAIJ, B. van; KIEHL, J.C. de; PROCHNOW, L.I. Efeito na extração de fósforo em latossolo roxo por extratores químicos. In: $\mathrm{CON}$ GRESSO LATINO AMERICANO DE CIÊNCIA DO SOLO, 13., 1996, Águas de Lindóia. Solo suelo, 96. Campinas: Software Gráfico, [1996?]. 6par. CDROM. Seção Trabalhos.

PIHA, M.I. Evaluation of Mehlich-3 extractant for estimating phosphorus deficiency and phosphorus sorption of Zimbabwean soils. Communications in Soil Science and Plant Analysis, New York, v.24, p.1397-1408, 1993.

RAIJ, B. van. Algumas reflexões sobre análise de solo para recomendação de adubação. In: REUNIÃO BRASILEIRA DE FERTILIDADE DO SOLO E NUTRIÇÃO DE PLANTAS, 20., 1992, Campinas. Anais dos simpósios. Campinas: Fundação Cargill/SBSC, 1992. p.71-87.

RAIJ, B. van. Fertilidade do solo e adubação. Piracicaba: Agronômica Ceres/ POTAFOS, 1991. 343p.

RAIJ, B. van. New diagnostic techniques, universal soil extractants. Communications in Soil Science and Plant Analysis, New York, v.25, p.799-816, 1994.

RAIJ, B. van. Seleção de métodos de laboratórios para avaliar a disponibilidade de fósforo em solos. Revista Brasileira de Ciência do Solo, Campinas, v.2, p.1-9, 1978.

RAIJ, B. van; DIEST, A. van. Phosphate supplying power of rock phosphate in an oxisol. Plant and Soil, The Hague, v.55, p.97-104, 1980.

RAIJ, B. van; CABALA, R.P.; LOBATO, E. Adubação fosfatada no Brasil: apreciação geral, conclusões e recomendações. In: OLIVEIRA, A.J.; LOURENÇO, S; GOEDERT, W.J. (Eds.). Adubação fosfatada no Brasil. Brasília: Embrapa-DID, 1982. p.1-19. (Embrapa-DID. Documentos, 21). 
RAIJ, B. van; FEITOSA, C.T.; SILVA, N.M. da. Comparação de quatro extratores de fósforo de solos. Bragantia, Campinas, v.43, p.17-29, 1984.

RAIJ, B. van; QUAGGIO, J.A.; SILVA, N.M. da. Extraction of phosphorus, potassium, calcium, and magnesium from soils by an ion-exchange resin procedure. Communications in Soil Science and Plant Analysis, New York, v.17, p.547-566, 1986.

SFREDO, G.J; BORKERT, C.M.; CORDEIRO, D.S.; PALHANO, J.B.; DITTTRICH, R.C. Comparação de cinco extratores de fósforo do solo, considerandose o tempo de incorporação de três adubos fosfatados. Revista Brasileira de Ciência do Solo, Campinas, v.3, p.111-115, 1979.

SILVA, F.C. da. Avaliação da disponibilidade de fósforo por diversos extratores em solos cultivados com cana-de-açúcar (Saccharum spp.). Piracicaba: ESALQ, 1991. 164p. Tese de Mestrado.

SMITH, F.W.; ELLIS, B.G.; GRAVA, J. Use of acid-fluoride solution for the extraction of available phosphorus in calcareous soils and soils which rock phosphate has been added. Soil Science Society of America. Proceedings, Madison, v.21, p.400-404, 1957.

THOMAS, G.W.; PEASLEE, D.E. Testing soils for phosphorus. In: WALSH, L.M.; BEATON, J.D (Eds.). Soil testing and plant analysis. Madison: SSSA, 1973. p.115-132.

VASCONCELLOS, C.A.; BAHIA FILHO, A.F.E.C.; COELHO, A.M.; FREIRE, F.M.; PITTA, G.V. Extrator universal e a fertilidade de solo de Minas Gerais: um enfoque preliminar. [S.l.: s.n., 1996?]. Não paginado. Trabalho apresentado no XXI Congresso Nacional de Milho e Sorgo, Londrina, PR, jul. 1996. 